\title{
Minute ventilation and heart rate relationship for estimation of the ventilatory compensation point at high altitude: a pilot study
}

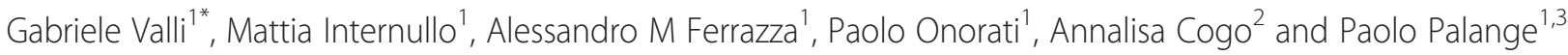

\begin{abstract}
Background: The ventilatory compensation point (VCP) is an exercise threshold which has been used in the design of training programs in sports medicine and rehabilitation. We recently demonstrated that changes in the slope of the minute ventilation to heart rate relationship $\left(\Delta \dot{V}_{E} / \Delta H R\right)$ can be utilized for estimation of the VCP during incremental exercise at sea level (SL). We hypothesized that in hypoxic conditions, such as high altitude (HA), VCP can be also reliably estimated by $\Delta \dot{V}_{E} / \Delta H R$.

Methods: At SL and on immediate ascent to HA $(5,050 \mathrm{~m})$, six healthy subjects (42 $\pm 14 \mathrm{SD}$ years) performed a maximal incremental exercise test on a cycle ergometer; $\mathrm{O}_{2}$ uptake $\left(\dot{V}_{\mathrm{O}_{2}}\right), \mathrm{CO}_{2}$ output $\left(\dot{V}_{\mathrm{CO}_{2}}\right), \dot{V}_{E_{1}}$ and HR were measured breath-by-breath. The $\Delta \dot{V}_{E} / \Delta \mathrm{HR}$ method for VCP estimation was compared to the standard method using the ventilatory equivalent for $\mathrm{CO}_{2}\left(\dot{V}_{E} / \dot{V}_{\mathrm{CO}_{2}}\right)$ and end-tidal $\mathrm{PCO}_{2}\left(\mathrm{P}_{\mathrm{ET}} \mathrm{CO}_{2}\right)$. The $\Delta \dot{V}_{E} / \Delta \mathrm{HR}$ slope values below $\left(S_{1}\right)$ and above $\left(S_{2}\right)$ VCP were computed by linear regression analysis.

Results: A significant difference between $S_{1}$ and $S_{2}$ was observed, at $S L$ and $H A$, for both the $\Delta \dot{V}_{E} / \Delta H R$ and $\dot{V}_{E} / \dot{V}_{\mathrm{CO}_{2}}$ methods for VCP estimation. A good agreement between the two methods $\left(\Delta \dot{V}_{E} / \Delta \mathrm{HR}\right.$ vs. $\left.\dot{V}_{E} / \dot{V}_{\mathrm{CO}_{2}}\right)$ was found for both environmental conditions; the mean difference \pm 2 SD of $\dot{V}_{\mathrm{O}_{2}}$ at VCP (VCP- $\dot{V}_{\mathrm{O}_{2}}$ ) was $-22 \pm 112 \mathrm{ml} /$ min at $\mathrm{SL}$ and $39 \pm 81 \mathrm{ml} / \mathrm{min}$ at $\mathrm{HA}$. The VCP- $\dot{\mathrm{V}}_{\mathrm{O}_{2}}$ was significantly lower at HA compared to SL; in addition, $\mathrm{S}_{1}$ and $\mathrm{S}_{2}$ mean values were significantly higher at $\mathrm{HA}$ compared to $\mathrm{SL}$.
\end{abstract}

Conclusion: At HA, VCP may be reliably estimated by the $\Delta \dot{V}_{E} / \Delta \mathrm{HR}$ method.

Keywords: High altitude, Ventilatory compensation point, Exercise, Ventilation, Heart rate

\section{Background}

In normal individuals, minute ventilation $\left(\dot{V}_{E}\right)$ during exercise displays a more marked rapid increase when work rate exceeds the heavy-intensity domains, as a compensatory effect of the metabolic acidosis [1,2], and this threshold is called the ventilatory compensation point (VCP) [3]. The VCP has been utilized for the design of training programs in sports medicine and rehabilitation [4,5]. Practical and, in some instances, simple approaches for estimation of the VCP have been evaluated in the past by different authors. Several

\footnotetext{
* Correspondence: gabvalli@yahoo.it

'Lung Function Unit, Department of Public Health and Infectious Diseases, University of Rome "La Sapienza", viale Università 37, Rome 00185, Italy Full list of author information is available at the end of the article
}

strategies have been proposed, based either on $\dot{V}_{E}$ [6] or heart rate $(\mathrm{HR})$ responses $[7,8]$.

Since HR is usually reasonably linear with respect to oxygen uptake $\left(\dot{V}_{\mathrm{O}_{2}}\right)$ over the entire work rate range [9], we have argued that the changes in the slope of increment in $\dot{V}_{E}$ over HR response $\left(\Delta \dot{V}_{E} / \Delta \mathrm{HR}\right)$ can be utilized to estimate VCP during incremental exercise at sea level (SL) $[10,11]$. The $\Delta \dot{V}_{E} / \Delta \mathrm{HR}$ method has shown a good agreement with the standard method for VCP estimation (i.e., increased ventilatory equivalent for $\mathrm{CO}_{2}$ $\left.\dot{V}_{E} / \dot{V}_{\mathrm{CO}_{2}}\right)$ and decreased end-tidal $\mathrm{PCO}_{2}\left(\mathrm{P}_{\mathrm{ET}} \mathrm{CO}_{2}\right)$, independently of exercise modality [11] and protocol [10]. The $\Delta \dot{V}_{E} / \Delta \mathrm{HR}$ method therefore may be a potentially promising method to estimate VCP during field tests or in difficult environmental conditions.

\section{C) Biomed Central}

(c) 2013 Valli et al.; licensee BioMed Central Ltd. This is an Open Access article distributed under the terms of the Creative Commons Attribution License (http://creativecommons.org/licenses/by/2.0), which permits unrestricted use, distribution, and reproduction in any medium, provided the original work is properly cited. 
At high altitude (HA), compared to $\mathrm{SL}, \dot{V}_{E}$ is greatly increased at any given work rate [12]. This may have a detrimental effect on exercise tolerance because it may lead to a significant reduction in ventilatory reserve [13]; however, reduced regional blood flow and oxygen diffusion limitation in the lungs and exercising muscles are also believed to play an important role in limiting exercise tolerance at HA [14]. The HR response at any given work rate is also increased at HA [15], although maximal HR appears to be reduced [13-16]. No data, however, are available on the slopes of the $\Delta \dot{V}_{E} / \Delta \mathrm{HR}$ response to exercise at HA.

In the present study, we wanted to establish the reliability of the $\Delta \dot{V}_{E} / \Delta \mathrm{HR}$ method for the estimation of $\mathrm{VCP}$ at HA, an environmental condition associated with an augmented ventilatory and cardiac response to exercise. We hypothesized that the $\Delta \dot{V}_{E} / \Delta \mathrm{HR}$ method at $\mathrm{HA}$ would be as reliable as the standard method for VCP estimation. If so, this could lead to the development of less expensive exercise equipment, i.e., without gas analyzers, that could readily be easily used in sports medicine and in high altitude studies where calibaration of gas analyzers is more difficult.

\section{Methods}

\section{Subjects}

Six healthy non-smoking SL resident subjects (two females, four males; Table 1) provided written informed consent to participate in the study. The procedures and protocols were approved by the National Research Council (CNR, Italy) as part of the Ev-K2-CNR research program and were conducted in accordance with the Declaration of Helsinki.

\section{Protocols}

The SL phase was conducted in Rome, Italy, at approximately $60 \mathrm{~m}$ of altitude. On day 1, the subjects performed standard pulmonary function tests and got familiarized with the maximal incremental exercise test.

Table 1 Subjects' baseline characteristics

\begin{tabular}{ll}
\hline Baseline characteristic & Value \\
\hline Age (years) & $41 \pm 15$ \\
Height $(\mathrm{cm})$ & $1.74 \pm 0.10$ \\
$\mathrm{BMI}\left(\mathrm{kg} / \mathrm{m}^{2}\right)$ & $23.6 \pm 2.9$ \\
$\mathrm{FVC}$ at SL (I, \%pred) & $4.70 \pm 0.90,103 \pm 14$ \\
FEV 1 at SL (I, \%pred) & $3.77 \pm 0.75,109 \pm 16$ \\
FVC at HA (l, \%pred) & $4.59 \pm 0.99,100 \pm 14$ \\
FEV ${ }_{1}$ at $\mathrm{HA}(\mathrm{l}, \%$ pred) & $3.79 \pm 0.98,106 \pm 17$ \\
\hline
\end{tabular}

FVC, forced vital capacity; FEV, forced expiratory volume; \%pred, percent predicted.
On the subsequent day, the formal maximal incremental exercise test was conducted until exhaustion.

The HA phase of the study was conducted at the CNR Pyramid Laboratory, Lobuche, Khumbu, Nepal (5,050 m, barometric pressure approximately 410 Torr). After travelling by plane through Kathmandu (1,340 m) up to Lukla $(2,860 \mathrm{~m})$, all subjects performed a 10-day trek to the Pyramid Laboratory with the following intermediate stops for acclimatization: 3 days at Namche Bazaar $(3,450 \mathrm{~m})$ and then 2 days at Pheriche $(4,252 \mathrm{~m})$. Symptoms of acute mountain sickness and resting arterial $\mathrm{O}_{2}$ saturation $\left(\mathrm{SpO}_{2}\right)$ were monitored. After 1 day of rest at the Pyramid Laboratory, the experimental phase started. On day 2, the subjects performed standard pulmonary function tests. Calibration of the spirometer (photoelectric digital turbine, diameter $28 \mathrm{~mm}$, resolution $4 \mathrm{ml}$, Micro Kit, COSMED, Rome, Italy) was performed prior to each test, using a 3-1 syringe.

\section{Incremental exercise test}

On day 3, each subject performed a maximal incremental exercise test on a cycle ergometer. The pedaling frequency was set at $60 \pm 5 \mathrm{rpm}$ by subjects following an electronic audio signal generated each second. The test protocol consisted (a) 2 min of rest, (b) 4 min of exercise at $20 \mathrm{~W}$, (c) the incremental phase with work rate increments of 15 $\mathrm{W} / \mathrm{min}$ at $\mathrm{HA}$ and $25 \mathrm{~W} / \mathrm{min}$ at SL, (d) 6 min of recovery pedalling at $20 \mathrm{~W} . \mathrm{O}_{2}$ uptake $\left(\dot{V}_{\mathrm{O}_{2}}\right.$, standard temperature and pressure, dry (STPD)), $\mathrm{CO}_{2}$ output ( $\left.\dot{V}_{\mathrm{CO}_{2}}, \mathrm{STPD}\right)$, minute ventilation ( $\dot{V}_{E}$, body temperature and pressure saturated BTPS), and end-tidal partial pressures for $\mathrm{O}_{2}$ and $\mathrm{CO}_{2}\left(\mathrm{P}_{\mathrm{ET}} \mathrm{O}_{2}, \mathrm{P}_{\mathrm{ET}} \mathrm{CO}_{2}\right)$ were obtained breath-by-breath and edited to exclude occasional outlying breaths $(> \pm 4 \mathrm{SD}$ of the local mean) as a result of coughs, swallows, sighing, or gasping. A 10-s average was utilized for subsequent analysis.

For VCP estimation by analysis of the $\Delta \dot{V}_{E} / \Delta \mathrm{HR}$ relationship $\left(\mathrm{VCP}_{\dot{V}_{E} / \mathrm{HR}}\right)$, we utilized a least squares regression analysis. Using a dedicated software, we applied a 'best fit' line to the data which extended from end-exercise back to the sub-maximal point at which the linearity was lost $\left(\mathrm{S}_{2}\right.$ region); this breakpoint was compared with the standard approach for VCP estimation $\left(\mathrm{VCP}_{\dot{V}_{E} / \dot{V}_{\mathrm{CO}_{2}}}\right)$ based on the $\dot{V}_{E} / \dot{V}_{\mathrm{CO}_{2}}$ relationship, where $\dot{V}_{E}$ started to change out of proportion of $\dot{V}_{\mathrm{CO}_{2}}$ and $\mathrm{P}_{\mathrm{ET}} \mathrm{CO}_{2}$ started to fall [17]. From the aforementioned breakpoint, a second best fit line $\left(\mathrm{S}_{1}\right)$ was applied to the data extending from the end of the warm-up phase upwards into the exercise data. If a second breakpoint was discernible, the $S_{1}$ line was then divided in two different regions $\left(\mathrm{S}_{1}\right.$ " from the breakpoint to $\mathrm{VCP}_{\dot{V}_{E} / \mathrm{HR}}$ and $\mathrm{S}_{1}$ ' from the end of warm-up up to the observed breakpoint), and the HR value at this breakpoint 
was then compared with the value observed at lactate threshold $\left(\theta_{\mathrm{L}}\right.$, estimated by the 'V-slope method' [3] and supported by standard ventilatory equivalent and endtidal gas tension criteria [17]).

\section{Equipment}

The incremental exercise test was performed on a mechanically braked cycle ergometer (828E, Monark Exercise AB, Varberg, Sweden). Prior to each test, the zero-load setting on the ergometer was checked, and a calibration was performed with a 4-kg weight. Ventilatory and pulmonary gas exchange variables were measured breath-by -breath in all tests using a portable system $\left(\mathrm{K}_{4} \mathrm{~b}^{2}\right.$, COSMED) which has been previously validated at HA [18]; the accuracy of the telemetric system has been previously established $[18,19]$. The system comprised a face mask, analyzer unit (containing $\mathrm{O}_{2}$ and $\mathrm{CO}_{2}$ gas analyzers), heart rate monitor, and battery. The analyzer unit with battery pack, face mask, and tubing (weight 0.8 $\mathrm{kg}$ ) was attached to the subject with a harness and connected to a personal computer by an Ethernet cable connection. The face mask contained a turbine for measurement of volume and flow; calibration was performed with a 3-1 syringe (Hans Rudolph, Kansas City, MO, USA) over a range of different flow profiles. Respired gas, sampled continuously from a port within the turbine via a Nafion polymer capillary (PermaPure $\odot$, Toms River, NJ, USA), was analyzed at $100 \mathrm{~Hz}$ using rapid-response $\mathrm{O}_{2}$ (polarographic) and $\mathrm{CO}_{2}$ (infrared) analyzers (mean response time $120 \mathrm{~ms}$ ) which were automatically thermostated and compensated for ambient variations in barometric pressure, humidity, and environmental temperature. Analyzers' calibration was performed using two precision-analyzed gas mixtures spanning the respired range. The volume and gas concentration signals were sampled and digitized every 10 $\mathrm{ms}$, and time-aligned, i.e., correcting for the transport delay between the turbine and gas analyzers and for the analyzer rise time [20]. HR was measured from a chest strip and recorded every breath. $\mathrm{SpO}_{2}$ was monitored non-invasively by finger pulse oximetry (Masimo Rad-5, Masimo Corporation, Irvine, CA, USA).

\section{Statistical analyses}

Differences among measured responses were determined by a Student's paired $t$ test. Pearson's product-moment correlation coefficient $\left(R^{2}\right)$ was used to identify correlations between criterion variables. The level of statistical significance was set at $\mathrm{P}<0.05$. Group data are presented as mean $\pm \mathrm{SD}$. The limits of agreement between the $\dot{V}_{E} / \dot{V}_{\mathrm{CO}_{2}}$ and the $\Delta \dot{V}_{E} / \Delta \mathrm{HR}$ methods for VCP estimation were evaluated by the Bland-Altman analysis [21], where the individual differences are plotted against their respective means. We proceeded with such a type of analysis if a significant linear correlation between methods was previously observed. The same statistical approach was also performed to compare the correspondence between $\theta_{\mathrm{L}}$ and the breakpoint between $\mathrm{S}_{1}$ " and $\mathrm{S}_{1}{ }^{\prime}$ in the $\Delta \dot{V}_{E} / \Delta \mathrm{HR}$ relationship, when the latter was detectable.

\section{Results}

The main results of the incremental tests are illustrated in Table 2. At HA, compared to SL, a significant reduction in $\dot{V}_{\mathrm{O}_{2} \text { peaks }}, \mathrm{WR}_{\text {peak }}, \mathrm{HR}_{\text {peak }}, \mathrm{SpO}_{2 \text { peak }}$, and $\theta_{\mathrm{L}}$ was observed; on the contrary, $\dot{V}_{\text {Epeak }}$ at HA was appreciably higher.

Figures 1 and 2 show $\Delta \dot{V}_{E} / \Delta_{\mathrm{O}_{2}}, \dot{V}_{E} / \dot{V}_{\mathrm{CO}_{2}}, \mathrm{P}_{\mathrm{ET}} \mathrm{O}_{2}$, $\mathrm{P}_{\mathrm{ET}} \mathrm{CO}_{2}$ vs. $\dot{V}_{\mathrm{CO}_{2}}$, and $\Delta \dot{V}_{E} / \Delta \mathrm{HR}$ relationship in two representative subjects at SL (upper panels) and HA (lower panels). As shown in Figure 3, in all subjects, a breakpoint in $\Delta \dot{V}_{E} / \Delta \mathrm{HR}$, which occurred at the VCP estimated by the $\dot{V}_{E} / \dot{V}_{\mathrm{CO}_{2}}$ method, was clearly discernible both at SL and HA. No significant differences were found in $\dot{V}_{\mathrm{O}_{2}}$ measured at VCP $\left(\dot{V}_{\mathrm{CO}_{2}}-\mathrm{VCP}\right.$; Table 3) between methods utilized to identify the threshold (VCP- $\Delta \dot{V}_{E} / \Delta$ HR vs. VCP- $\dot{V}_{E} / \dot{V}_{\mathrm{CO}_{2}}$ ).

The Bland-Altman analysis confirmed the agreement between the $\dot{V}_{E} / \dot{V}_{\mathrm{CO}_{2}}$ and $\Delta \dot{V}_{E} / \Delta \mathrm{HR}$ methods in estimating VCP, both at SL and at HA (Figure 4, Table 3); the mean bias $\pm 95 \%$ confidence interval of the betweenmethod differences were $-22 \pm 112 \mathrm{ml} / \mathrm{min}$ of $\dot{V}_{\mathrm{O}_{2}}$ for the SL protocol and $39 \pm 81 \mathrm{ml} / \mathrm{min}$ of $\dot{V}_{\mathrm{O}_{2}}$ for the HA protocol (Figure 4).

Although in some instances a lower breakpoint in the $\mathrm{S}_{1}$ region was observed (four out of six subjects at SL and one out of six at HA), no significant agreement between such a breakpoint and the $\theta_{\mathrm{L}}$ was obtained in terms of HR and $\dot{V}_{\mathrm{O}_{2}}$ values. $\dot{V}_{\mathrm{Otry1}_{2}}$-VCP was significantly lower at HA (approximately $500 \mathrm{ml}$ of $\dot{V}_{\mathrm{O}_{2}}$ less)

Table 2 Results of the incremental exercise tests at HA and SL

\begin{tabular}{llll}
\hline & HA & SL & $P$ value \\
\hline $\mathrm{SpO}_{\text {2peak }}(\%)$ & $72.8 \pm 7.3$ & $98 \pm 1.4$ & $<0.001$ \\
$\mathrm{WR}_{\text {peak }}(\mathrm{W})$ & $138 \pm 26$ & $208 \pm 44$ & $<0.01$ \\
$\dot{V}_{O_{2 \text { peak }}}(\mathrm{ml} / \mathrm{min})$ & $1,690 \pm 533$ & $2,227 \pm 511$ & $<0.01$ \\
$\dot{V}_{\mathrm{CO}_{\text {2peak }}}(\mathrm{ml} / \mathrm{min})$ & $2,060 \pm 570$ & $2,820 \pm 780$ & $<0.01$ \\
$\dot{V}_{\text {Epeak }}(\mathrm{l} / \mathrm{min})$ & $123.4 \pm 33.3$ & $91.3 \pm 28.6$ & $<0.01$ \\
$\theta_{\mathrm{L}}(\mathrm{ml} / \mathrm{min})$ & $1,015 \pm 222$ & $1,302 \pm 241$ & $<0.01$ \\
$\mathrm{HR}_{\text {peak }}(\mathrm{bpm} / \mathrm{min})$ & $147 \pm 13$ & $168 \pm 12$ & $<0.001$ \\
\hline
\end{tabular}



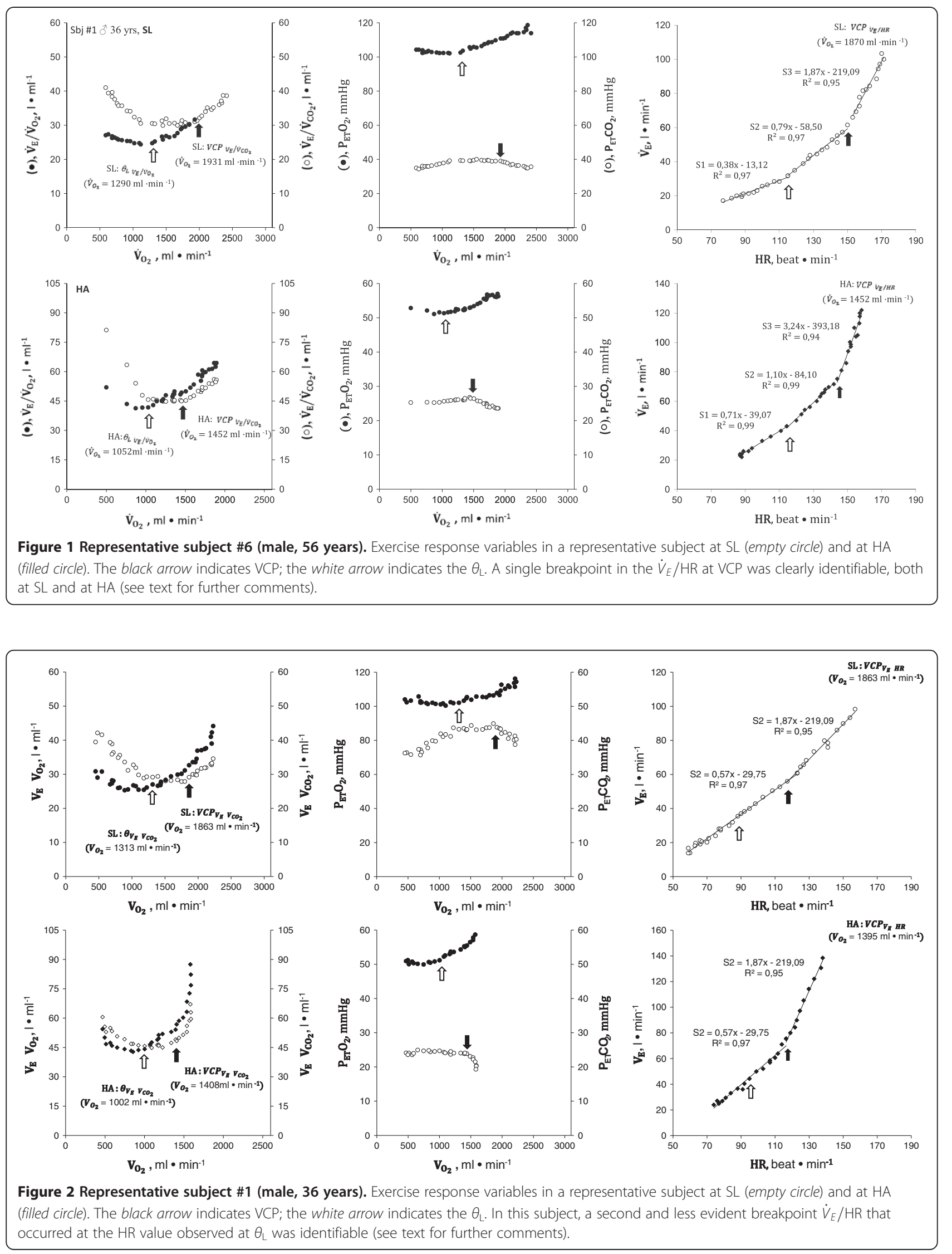


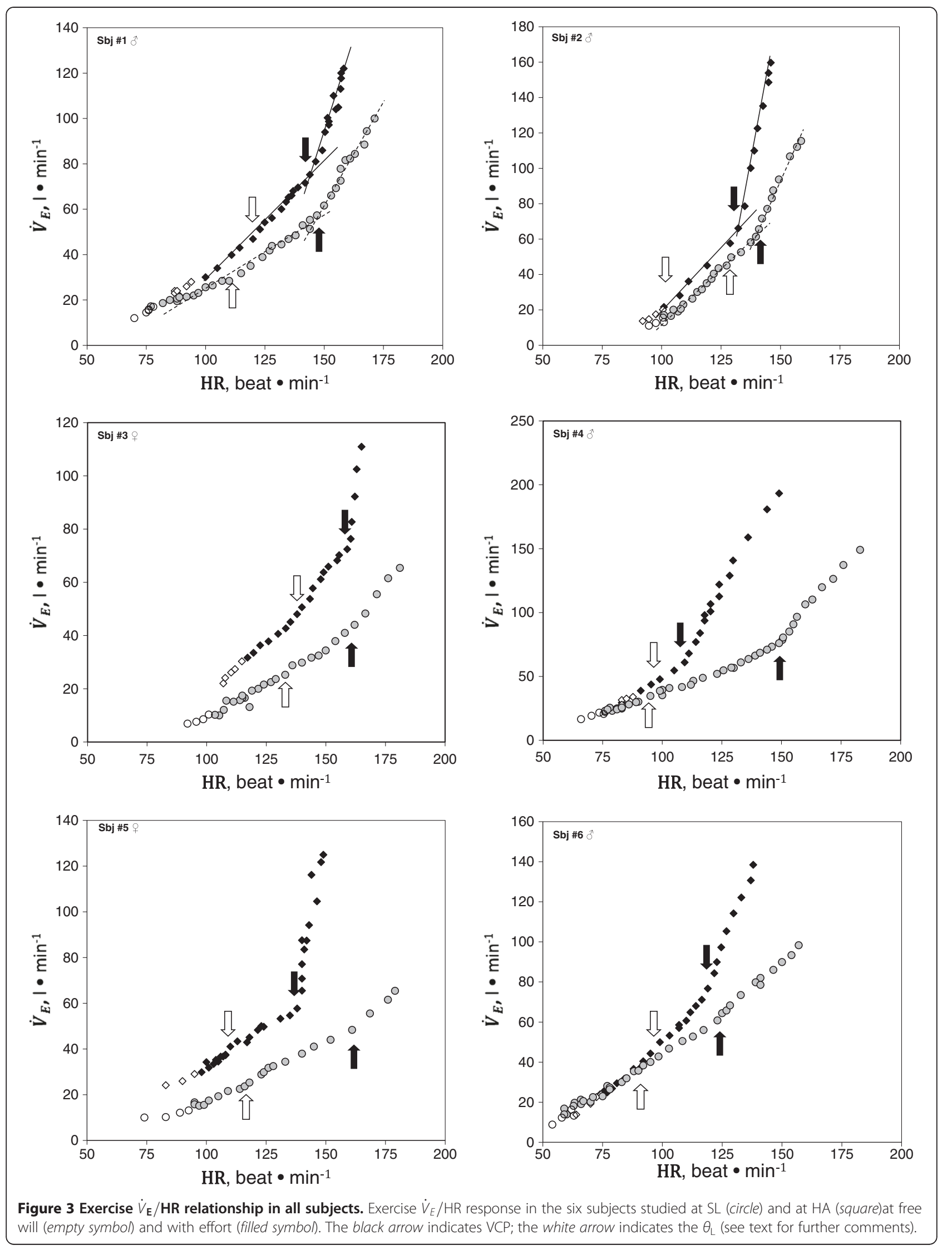


Table 3 VCP, $S_{1}$, and $S_{2}$ values at HA and SL

\begin{tabular}{llll}
\hline & HA & SL & $P$ value \\
\hline $\mathrm{VCP}-\Delta \dot{V}_{E} / \Delta \mathrm{HR}(\mathrm{ml} / \mathrm{min})$ & $1,325.3 \pm 214.7$ & $1,822.0 \pm 371.6$ & $<0.05$ \\
$\mathrm{VCP}-\dot{V}_{E} / \dot{V}_{\mathrm{CO}_{2}}(\mathrm{ml} / \mathrm{min})$ & $1,315.1 \pm 180.8$ & $1,839.1 \pm 359.5$ & $<0.05$ \\
$S_{1_{\dot{V}_{E} / \mathrm{HR}}}(\mathrm{l} / \mathrm{bp})$ & $1.09 \pm 0.33$ & $0.76 \pm 0.32$ & $<0.01$ \\
$S_{2_{\dot{V}_{E} / \mathrm{HR}}}(\mathrm{l} / \mathrm{bp})$ & $4.8 \pm 2.5$ & $1.4 \pm 0.6$ & $<0.05$ \\
$S_{1_{\dot{V}_{E} / \dot{V O}_{\mathrm{CO}}}}$ & $0.043 \pm 0.005$ & $0.025 \pm 0.001$ & $<0.01$ \\
$S_{2_{\dot{V}_{E} / \dot{C O}_{2}}}$ & $0.114 \pm 0.052$ & $0.047 \pm 0.01$ & $<0.05$ \\
$S_{2} / S_{1_{\dot{V}_{E} / \mathrm{HR}}}$ & $4.5 \pm 1.9$ & $2.0 \pm 0.8$ & $\mathrm{NS}$ \\
$S_{2} / S_{1_{\dot{V}_{E} / V \mathrm{CO}_{2}}}$ & $2.7 \pm 1.5$ & $1.9 \pm 0.4$ & $\mathrm{NS}$ \\
\hline
\end{tabular}

NS, not significant.

independently of the method utilized to estimate it, as shown in Table 2.

$S_{1}$ and $S_{2}$ at HA were significantly higher for both $\Delta \dot{V}_{E} / \Delta \mathrm{HR}$ and $\dot{V}_{E} / \dot{V}_{\mathrm{CO}_{2}}$ methods (Table 3). The ratio $\mathrm{S}_{2} / \mathrm{S}_{1}$ tended to be higher at $\mathrm{HA}$ regardless of the estimation method utilized (Table 3), and this was particularly so for the $\Delta \dot{V}_{E} / \Delta \mathrm{HR}$ method.

\section{Discussion and conclusions}

The main findings of this study are as follows: (1) VCP is clearly identifiable during incremental exercise at HA; (2) in conditions of persistent hypoxia, such as that elicited by HA exposure, VCP can be easily estimated by the $\Delta \dot{V}_{E} / \Delta \mathrm{HR}$ analysis. In the present study on young healthy individuals, applying standard methods for the identification, VCP could be identified both at SL and HA. Our data are in accordance with the observation of Agostoni et al,, who demonstrated that at HA the VCP was clearly identifiable [22].

Of note, we observed a $30 \%$ reduction in $\dot{V}_{\mathrm{O}_{2}}$-VCP when moving from SL to HA. The lower VCP at HA likely reflected the shortening of the isocapnic buffering period because of the increased hypoxic sensitivity of the carotid chemoreflex [22]. A further influence was presumably the premature development of metabolic acidosis during exercise at $\mathrm{HA}$, as demonstrated by the lower $\theta_{\mathrm{L}}$ likely due both to the reduction in arterial $\mathrm{O}_{2}$ content and impaired convective $\mathrm{O}_{2}$ transport to the exercising muscles [23].

Importantly, as demonstrated by the Bland-Altman analysis, we were able to demonstrate that the $\Delta \dot{V}_{E} /$ $\triangle \mathrm{HR}$ approach is a reliable method for VCP estimation during incremental exercise at HA. The limits of agreement and the coefficient of variation between the $\dot{V}_{E} /$ $\dot{V}_{\mathrm{CO}_{2}}$ and $\Delta \dot{V}_{E} / \Delta \mathrm{HR}$ methods for VCP estimation are quite narrow and likely to fall within the between-day intra-subject $\dot{V}_{\mathrm{O}_{2}}$ variability [24].

The results of the present study are in agreement with a previous work of our group that demonstrated the reliability of the $\Delta \dot{V}_{E} / \Delta \mathrm{HR}$ breakpoint for VCP estimation at SL during incremental exercise [10,11]. At SL, assuming a linear relationship between $\dot{V}_{E}$ and HR (at least up to the heavy-intensity domain), the steepening of the $\Delta \dot{V}_{E} / \Delta$ HR slope is more evident above VCP where (1) a steeper increase in $\dot{V}_{E} / O_{2}$ relationship is expected [9] and (2) the HR response could either maintain the same linearity as for more moderate exercise or in some instances (depending on exercise performance and protocol) reduce its rate of increment with respect to work rate [25]. Interestingly, at HA, we observed higher $\mathrm{S}_{1}$ and $\mathrm{S}_{2} \Delta \dot{V}_{E} / \Delta \mathrm{HR}$ slopes. These findings are in accordance with previous studies demonstrating that $\dot{V}_{E}$ at rest and at any given work rate during exercise is increased at HA because of the greater hypoxic drive [12-26] and also because of the reduction in the rate of
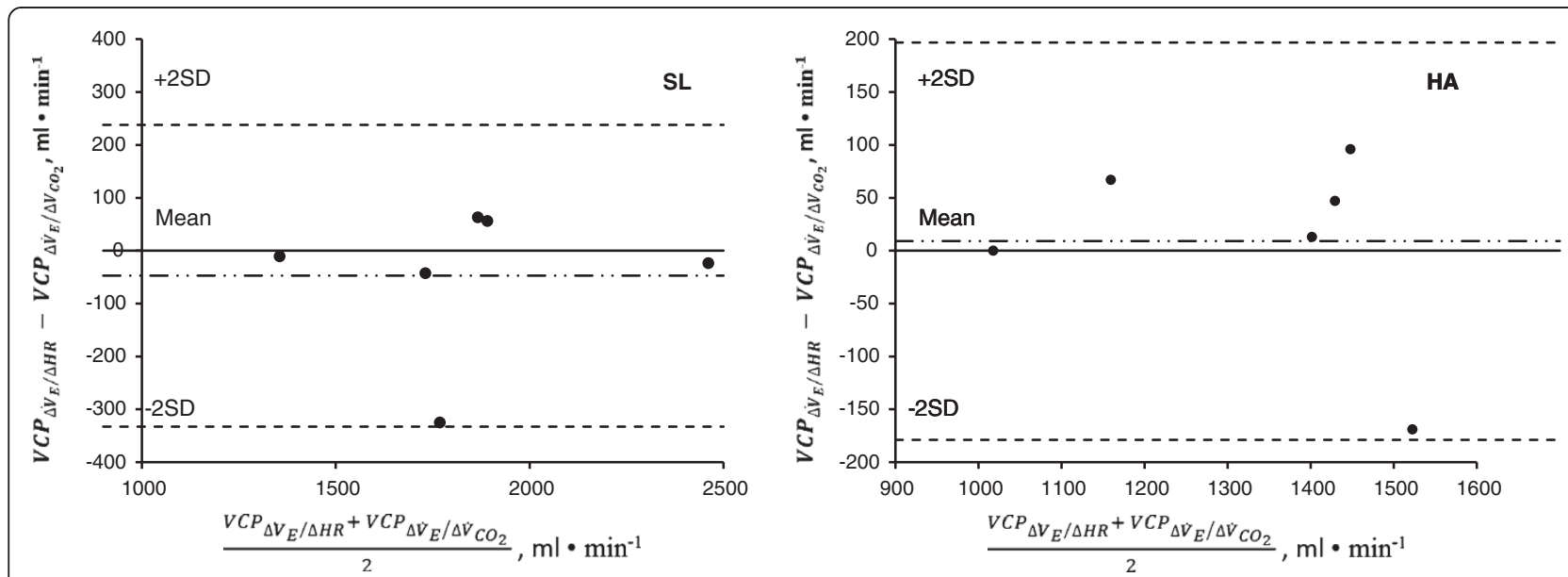

Figure 4 Bland-Altman analysis. The Bland-Altman analysis confirmed the agreement between the $\dot{V}_{E} / \dot{V}_{\mathrm{CO}_{2}}$ and $\dot{V}_{E} / \mathrm{HR}$ methods in estimating VCP, both at SL and at HA. 
increase in HR between rest and peak exercise that is commonly observed at HA $[15,16]$. Moreover, compared to $S L$, we observed an increase in the $S_{2} / S_{1}$ ratio for $\Delta \dot{V}_{E} / \Delta \mathrm{HR}$ at HA. This finding suggests that $\mathrm{S}_{2}$ is influenced both by hypoxic ventilatory drive and possibly by an augmented contribution to $\dot{V}_{E}$ from the metabolic acidosis above the VCP [1]. However, our reasoning remains speculative as, for technical reasons, we were unable to measure arterial (or arterialized) [lactate] or $\mathrm{pH}$ during the exercise.

Below VCP, an earlier (in the $S_{1}$ region) but less evident breakpoint in $\Delta \dot{V}_{E} / \Delta \mathrm{HR}$ was discernible in some instances (5 out of 12), but only in one out five cases such a breakpoint was coincident with the anaerobic threshold.

We are aware that our study has limitations, particularly with regard to the small sample size and the constrained characteristics of our study population, which prevented the evaluation of factors such as age, sex, and level of fitness, each of which is known to influence the variables of interest. Also, we are aware (1) that the choice of a rapid work rate incremental protocol may have influenced the results utilized, i.e., different results may be observed if a slower work rate increment protocol is used, and (2) of the lack of validation for pulmonary gas exchange measurement at HA. We took precautions to limit errors in the calibration procedures, with all equipment being calibrated before each test and all tests being performed indoors in the Pyramid Laboratory at an ambient temperature of approximately $20^{\circ} \mathrm{C}$ and the necessary corrections for barometric pressure, humidity, and environmental temperature being applied through the dedicated software. Thus, our investigation should be considered as a pilot study conducted at extreme altitude, with the conclusions only being applicable to healthy untrained young adults.

In conclusion, we were able to demonstrate the reliability of the $\Delta \dot{V}_{E} / \Delta \mathrm{HR}$ method for the estimation of $\mathrm{VCP}$ at HA in a small group of sea-level residents, an environmental condition associated with different ventilatory and cardiac responses to exercise compared to SL. The attraction of the $\Delta \dot{V}_{E} / \Delta \mathrm{HR}$ method is that it is a less expensive method for VCP estimation, compared to those that utilize expired gas measurements, and may therefore be utilized in sports medicine and in extreme conditions such as high altitude.

\section{Competing interests}

The authors declare that they have no competing interests.

\section{Authors' contributions}

GV was the principal investigator, conceived the study, participated in all phases of the research, and drafted the manuscript. MI and AMF participated in the design of the study and in the data collection and performed the statistical analysis. PO helped conceive the study, participated in its design and coordination, and helped draft the manuscript. AC participated in the logistic organization, coordinated the research during the HA phase of the study that was conducted at the CNR Pyramid Laboratory, Lobuche, Khumbu, Nepal, and critically revised the final draft. PP helped conceive the study, supervised all phases of the research, helped in its design and coordination, and revised critically the manuscript. All authors read and approved the final manuscript.

\section{Acknowledgments}

This study was carried out within the framework of the Ev-K2-CNR Project in collaboration with the Nepal Academy of Science and Technology, and the authors wish to thank the Italian National Research Council and the Italian Ministry of Foreign Affairs for their financial assistance.

\section{Author details}

${ }^{1}$ Lung Function Unit, Department of Public Health and Infectious Diseases, University of Rome "La Sapienza", viale Università 37, Rome 00185, Italy. ${ }^{2}$ Biomedical Sport Studies Center, University of Ferrara, Via Gramicia 35, Ferrara 44123, Italy. ${ }^{3}$ Eleonora Lorillard Spencer Cenci Foundation, Piazzale Aldo Moro n. 5, Rome 00185, Italy.

Received: 19 June 2012 Accepted: 11 January 2013

Published: 1 March 2013

\section{References}

1. Wassermann K, Whipp BJ, Koyal SN, Beaver WL: Anaerobic threshold and respiratory gas exchange during exercise. J Appl Physiol 1973, 35(2):236-243.

2. Meyer T, Faude O, Scharhag J, Urhausen A, Kindermann W: Is lactic acidosis a cause of exercise induced hyperventilation at the respiratory compensation point? Br J Sports Med 2004, 38(5):622-625.

3. Beaver WL, Wasserman K, Whipp BJ: A new method for detecting anaerobic threshold by gas exchange. J Appl Physiol 1986, 60:2020-2027.

4. Azevedo LF, Perlingeiro PS, Brum PC, Braga AM, Negrão CE, de Matos LD: Exercise intensity optimization for men with high cardiorespiratory fitness. J Sports Sci 2011, 29(6):555-561.

5. Carvalho VO, Mezzani A: Aerobic exercise training intensity in patients with chronic heart failure: principles of assessment and prescription. Eur J Cardiovasc Prev Rehabil 2011, 18(1):5-14.

6. Neder JA, Stein R: A simplified strategy for the estimation of the exercise ventilatory thresholds. Med Sci Sports Exerc 2006, 38(5):1007-1013.

7. Conconi F, Ferrari MP, Ziglio G, Droghetti P, Codeca L: Determination of the anaerobic threshold by a noninvasive field test in runners. $J$ Appl Physiol 1982, 52:869-873.

8. Karapetian GK, Engels HJ, Gretebeck RJ: Use heart rate variability to estimate LT and VT. Int J Sports Med 2008, 29(8):652-657.

9. Wassermann K, Hansen JE, Sue DY, Casaburi R, Whipp BJ: Principles of Exercise Testing and Interpretation. 4th edition. Baltimore: Lippincott Williams \& Wilkins; 2005:10-65.

10. Onorati P, Martolini D, Ora J, Valli G, Fedeli A, Palange P: Estimation of the exercise ventilatory compensation point by the analysis of the relationship between minute ventilation and heart rate. Eur J App/ Physiol 2008, 104(1):3-17.

11. Onorati P, Martolini D, Valli G, Laveneziana P, Marinelli P, Angelici E, Palange $P$ : A simplified approach for the estimation of the ventilatory compensation point. Med Sci Sports Exerc 2012, 44(4):716-724.

12. Sutton JR, Reeves JT, Wagner PD, Groves BM, Cymerman A, Malconian MK, Rock PB, Young PM, Walter SD, Huston CS: Operation Everest Il: oxygen transport during exercise at extreme simulated altitude. J App/ Physio/ 1988, 64:1309-1321.

13. Valli G, Cogo A, Passino C, Bonardi D, Morici G, Fasano V, Agnesi M, Bernardi $L$, Ferrazza AM, Ward SA, Palange P: Exercise intolerance at high altitude (5050m): critical power and W'. Respiratory Physiol \& Neurobiol 2011, 177(3):333-341.

14. Anholm JD, Foster GP: Con: Hypoxic pulmonary vasoconstriction is not a limiting factor of exercise at high altitude. High Alt Med Biol 2011, 12(4):313-317.

15. Vogel JA, Hartley LH, Cruz JC, Hogan RP: Cardiac output during exercise in sea level residents at sea level and high altitude. J Appl Physiol 1974, 36:169-172. 
16. Reeves JT, Groves BM, Sutton JR, Wagner PD, Cymermann A, Malconian MK, Rock PB, Young PM, Houston CS: Operation Everest II: preservation of cardiac function at extreme altitude. J Appl Physiol 1987, 63:531-539.

17. American Thoracic Society/American College of Chest Physicians: ATS/ACCP Statement on cardiopulmonary exercise testing. Am J Respir Crit Care Med 2003, 167:211-277.

18. Pattinson K, Myers S, Gardner-Thorpe C: Apparatus. Problems with capnography at high altitude. Anesthesia 2004, 59:69-72.

19. Palange P, Forte S, Onorati P, Manfredi F, Carlone S, Serra P: Ventilatory and metabolic adaptation to walking and cycling in patients with COPD. J Appl Physiol 2000, 88:1715-1720.

20. Beaver WL, Wasserman K, Whipp BJ: On-line computer analysis and breath-by-breath graphical display of exercise function tests. J Appl Physiol 1973, 34:128-132.

21. Bland JM, Altman DG: Statistical methods for assessing agreement between two methods of clinical measurement. Lancet 1986, 1(8476):307-310

22. Agostoni $P$, Valentini $M$, Magrì $D$, Revera M, Caldara G, Gregorini F, Bilo G, Styczkiewicz K, Savia G, Parati G: Disappearance of isocapnic buffering period during increasing work rate exercise at high altitude. Eur $\mathrm{J}$ Cardiovasc Prev Rehabil 2008, 15:354-358.

23. Lundby C, Sander M, van Hall G, Saltin B, Calbet JA: Maximal exercise and muscle oxygen extraction in acclimatizing lowlanders and high altitude natives. J Physiol 2006, 573:535-547.

24. Wergel-Kolmert U, Agehäll A, Rosenberg N, Wohlfart B: Day-to-day variation in oxygen consumption at submaximal loads during ergometer cycling by adolescents. Clin Physiol 2001, 19(2):161-168.

25. Bodner ME, Rhodes EC: A review of the concept of the heart rate deflection point. Sport Med 2000, 30(1):31-46.

26. Richalet JP, Robach P, Jarrot S, Schneider JC, Mason NP, Cauchy E, Herry JP, Bienvenu A, Gardette B, Gortan C: Operation Everest III (COMEX'97): effects of prolonged and progressive hypoxia on humans during a simulated ascent to $8848 \mathrm{~m}$ in a hypobaric chamber. Adv Exp Med Biol 1988, 74:323-333.

doi:10.1186/2046-7648-2-7

Cite this article as: Valli et al:: Minute ventilation and heart rate relationship for estimation of the ventilatory compensation point at high altitude: a pilot study. Extreme Physiology \& Medicine 2013 2:7.

\section{Submit your next manuscript to BioMed Central and take full advantage of:}

- Convenient online submission

- Thorough peer review

- No space constraints or color figure charges

- Immediate publication on acceptance

- Inclusion in PubMed, CAS, Scopus and Google Scholar

- Research which is freely available for redistribution 